DE DE GRUYTER

OPEN

DOI: 10.1515/jolace-2016-0029

\title{
Assessment preferences and learning styles in ESP
}

\author{
Ivana Simonova, University of Hradec Kralove, Czech Republic \\ ivana.simonova@uhk.cz
}

\begin{abstract}
The article deals with the research on assessment preferences reflected in learning styles within English for Specific Purposes (ESP) instruction on the higher education level. The sample group consisted of 287 respondents of the Faculty of Informatics and Management, University of Hradec Kralove, Czech Republic. The main objective of the research was to discover expected correlations between respondents' learning styles and relating preferences in selected assessment formats. Two questionnaires were applied to reach the objective; however, the expectations did not prove. The discovered findings were discussed within the world context.
\end{abstract}

Key words: learning style, assessment format, assessment preference, ESP

\section{Introduction}

Either emphasized, or rejected by some scientists (e.g. Coffield, 2004; Mitchell, 2004), within last four decades various learning styles theories have been set (e.g. Kolb, Kolb, 2005; Felder, 2010; Honey, Mumford, 2002; Honey et al. 2000, Johnston, 1996 etc.) and applied in teaching various subjects, including foreign languages. Even in the current period of i-society and e-society, it is generally accepted the process of instruction includes (at least) four phases - motivation to learning, explanation the learning content, fixing new knowledge and assessing the increase with learners (Comenius, 1946). To make this process easier, students' learning preferences should be accommodated (Šimonová, Poulová, 2012). Therefore teachers take efforts to adjust the learning process to individual learner's needs and preferences, which mostly means various types study materials and sources of information are provided to the learners, various activities are conducted to help them fix the new knowledge and apply it successfully in practice (Šimonová, 2013; Šimonová, 2015). For these purposes various ICT-enhanced tools may be helpful (Honey, 2010). However, the phase of assessing learners' knowledge is rarely included in the process of accommodating their preferences. Quite the contrary, the process of assessment is identical for all learners to be 'fair', which in practice means it is very 'unfair', as it does not reflect 
individual learners' preferences, as Leither states (Leither, 2011). She conducted research with students of Humanities, when giving them the choice to show what they know in two written formats - a multiple-choice test, or an open-answer essay. As expected, the experimental group where assessment preferences were reflected reached significantly higher test scores compared to the control group (Leither, 2011, p. 417).

Reflecting this finding, the research question was set whether there exists any correlation between individual learning styles and assessment preferences, particularly what the preferred ways (i.e. assessment formats) are through which learners of different learning styles can prove their knowledge to maximum extent.

Therefore, a research similar to Leither' s one was conducted at the Faculty of Informatics and Management, University of Hradec Kralove, Czech Republic, and to introduce and discuss its results is the main objective of this article.

\section{State-of-art in ESP teaching at the institution}

The Faculty of Informatics and Management (FIM), University of Hradec Kralove (UHK), Czech Republic, is an institution of a rather short history - it was established two decades ago. Currently, it has more than 2,500 students in bachelor, master and doctoral study programmes specialized in Applied Informatics, Information Management, Knowledge Management and System Engineering. Six semesters of English for Specific Purposes (ESP) were taught for more than 15 years. Then, the change was made from economic reasons and since 2013/14 academic year ESP has been taught for four semesters. The learning content has not been limited, which requires the process of instruction became more effective from both the teachers' and learners' side. As enhanced by ICT, particularly by the online courses in LMS Blackboard running both on immobile and mobile devices, individual learner's preferences were taken into account within selected approaches to acquiring the learning content and building new knowledge, mainly in the explanation and fixing phases. Additionally to traditionally applied motivation for foreign language (English) learning and to the fact the ESP focused on students of Information technologies (IT), the learners' motivation was supported by the use of latest technologies. The learning content covered IT topics, and reading, listening, speaking and writing skills were step-bystep developed within the four semesters. The increase in learners' knowledge was assessed by the written Czech-English translation (i.e. open-answer) test checking the grammar and professional vocabulary after each semester (ESP 1 4) and by oral exam in the form of dialogue with the teacher on two from approximately 150 pre-defined topics (ESP 2), or the presentation on any professionally focused topic related to the field of study or student' work. The topics reflect the latest developments in the IT field, as they are collected by the students as assignments in each semester from the professional sources available 
to them at work; unknown items of professional vocabulary are translated and the recordings of the texts in the mp3 format are added. The e-English IT Reader is edited after each semester, and all materials are also available in the LMS. The assessment formats in each semester are binding for all students, which means that learners' assessment preferences are not reflected within this concept.

\section{Research objective and hypotheses}

To collect feedback and possibly propose changes in the above described state, the research was conducted having two main objectives: (1) to discover correlations between individual learning preferences and assessment preferences and (2) to identify the preferences/rejections of the exploited assessment formats by the students of different learning styles. So as to reach these objectives, the following main hypothesis was set to be verified/falsified:

H: There exist/s preference/s of certain assessment format/s with students of different learning style/s.

As three assessment formats were considered within this research, following partial hypotheses were set:

H1: There exists preference of written Czech-English translation with students of different learning style/s.

H2: There exists preference of oral dialogue with students of different learning style/s.

H3: There exists preference of oral/written presentation with students of different learning style/s.

\section{Methods and tools}

Reflecting the research objectives, two tools were applied: (1) Learning Combination Inventory (LCI) and Assessment Format Questionnaire (AFP). The former one (LCI) is a standardized tool designed by Johnston (1996) which determines students' learning preferences through 28 statements. Respondents express their agreement or disagreement to the statements on the five-point Likert scale $(1$ - never ever, 2 - almost never, 3 - sometimes, 4 - almost always, 5 always). At the end, three open-answer questions are added, the second one dealing with the process of assessment: question 1 - What makes assignments frustrating for you?; question 2 - If you could choose, what would you do to show your teacher what you have learned?; question 3 - If you were the teacher, how would you have students learn? The final score determines the individual pattern of learning preferences of each student which consists of four approaches to information processing (Johnston, 1996: 51-54): 
- $\quad$ sequential type, which applies the step-by-step approach;

- precise type, which focuses on information details;

- technical type, which prefers concrete numbers, figures and diagrams;

- confluent type, which does not follow any of common ways but these students are creative and 'march to a different drummer'.

The latter tool (AFQ) was exploited to find out what assessment formats students prefer. The tool was designed in three phases. First, before this research started, a pilot group of 22 FIM students expressed their opinions in the openanswer format on question 2 of the LCI, i.e. If you could choose, what would you do to show your teacher what you have learned? Second, their answers were analyzed and a list of 18 assessment formats was set. Third, the list was piloted by another group of 48 FIM students; several unclear expressions were corrected and the AFQ was finalized. It included a rather wide scale of assessment choices - oral and written, individual, pair and team, pre-defined and unknown and their combinations. Each of these 18 items was evaluated on the ten-point Likert scale from 1 - I strongly prefer to 10 - I strongly reject. At the end of AFQ item 19 was added so as respondents could express any other comments relating to the process of assessment. Not a single student piloting the AFQ was included in the sample group described below.

\section{Research sample}

At the beginning, more than 300 FIM students enrolled in one of the above listed IT study programmes participated in the research. However, finally, only 287 of them completed the whole process of research from various (private) reasons. The research sample consisted of $58 \%$ of male and $42 \%$ of female respondents structured into five age groups ( $<20$ years: $2 \% ; 20-24$ years old: 64 \%; $25-29$ years old: $17 \%$; 30-39 years old: $14 \%$; 40+: $3 \%$ ), studying in the parttime $(78 \%)$ or full-time form (22\%). Both questionnaires were available to the sample group in the LMS.

\section{Results}

Data collected by LCI and AFQ were processed by the NCSS2007 statistic software by the method of frequency analysis. Findings are presented in three steps:

- LCI results,

- AFQ results,

- LCI - AFQ correlations.

\section{LCI results}


Been alert of the fact that individual learning style is the combination of various types, in this starting point of the research only the leading learning style of each respondent was considered. Those having equal values in two or more styles were comprised in the indifferent group. The LCI results are presented in table 1.

Table 1: LCI results

\begin{tabular}{|l|c|c|c|c|c|}
\hline & Sequential & Precise & Technical & Confluent & Indifferent \\
\hline Total $(\mathrm{n})$ & 141 & 38 & 71 & 29 & 8 \\
\hline Total $(\%)$ & 49 & 13 & 25 & 10 & 3 \\
\hline
\end{tabular}

The data show that nearly half of the respondents (49\%) have the sequential processing as the leading style, followed by technical processors (25\%); precise (13\%) and confluent ones (10\%). Eight respondents (3\%) were detected as indifferent types.

\section{AFQ results}

As mentioned above, 19 assessment formats were included into AFQ and considered by the sample group regardless the learning style preference. For the view of subjects of ESP $1-4$, following formats were under our focus:

- written Czech-English translation,

- oral student-teacher dialogue on selected topics,

- presentation on any professional IT topic, preferably dealing with student's work and/or the field of study, i.e. this format is the combination of written design of presentation following pre-defined conditions (professional vocabulary, style, grammar, layout, colours, font etc.), and oral performance in the monologue form, followed by replies to listeners' questions in the dialogue form; this assessment format was proposed by AFQ respondents as item 19.

Respondents' preferences and rejections are displayed in figure 1 (1 - I strongly prefer to 10 - I strongly reject).

The collected data show the most preferred assessment format was the oral/written presentation. Reflecting students' comments under item 19, the reason was they felt free in creating the content of the presentation and the required layout and structure even helped them express their ideas. This result was rather surprising for the researcher because when the topic of presentation was taught to the students, long discussions were conducted on these 'restrictions'. 
slovakEdu, o.z.

Figure 1: Respondents' preferences and rejections to selected assessment formats

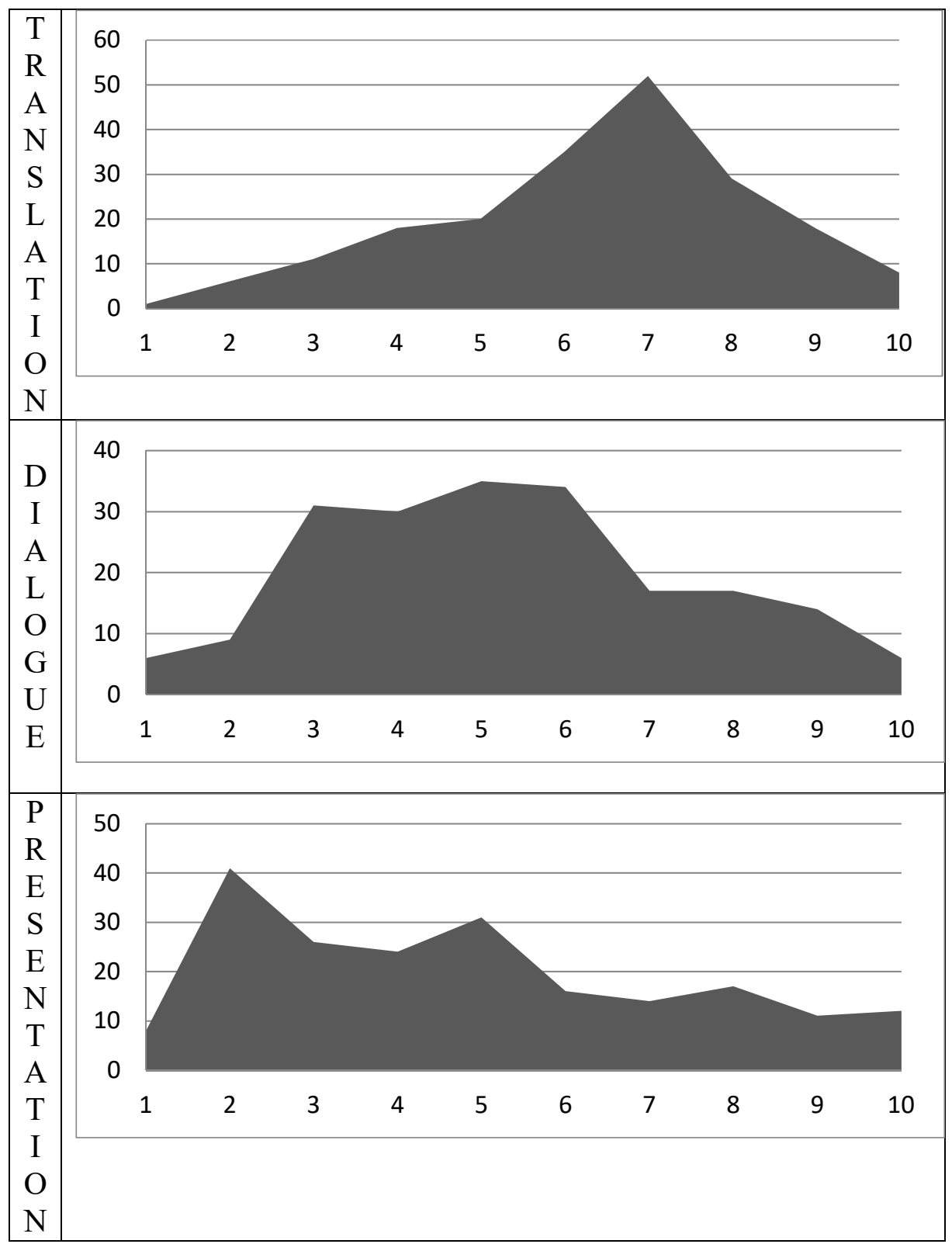


This opinion was presented by those students who had had some previous experience in designing commercial presentations. However, the main objective of such presentations is to be more eye-catching than to seriously introduce a certain content. On the other hand, this does not mean the students' school presentations should be boring and black-and-white only, however, the clear and unambiguous presentation of the content have strong preference to empty effects. Moreover, the presentation should work under various technical conditions, i.e. not only on the professional devices equipped with special (often paid) software which highly professional companies are equipped with but also on those available at the faculty which naturally cannot cover the whole field of IT profession. Students who had no or little experience in designing presentations appreciated the pre-defined rules. And, all students (with the exception of several ones having the proficiency knowledge) appreciated the vocabulary which they acknowledged during the semester and which helped them structure the presented content and join single parts meaningfully. Lack of, or no experience, was the reason why some students were very nervous before performing the presentation. Each of approximately 15 years, when the presentations have been conducted, about $5 \%$ of students did not finish their performances - either from the stress, or because they were not well prepared and felt ashamed of that.

The student-teacher dialogue over the professional texts also belongs to the preferred formats. There are several reasons. First, the texts are collected by students during the semester and unknown vocabulary is translated using the Insert comments tool. Then the source of text and students' name are provided and the texts are displayed in the LMS. It means the text are not anonymous works, but students make efforts to create their professional image of high quality. Second, students can read the texts individually and to such an extent which is appropriate to their level of English, so as they can be well prepared for the exam. Third, students know before the exam they will receive two texts selected by the teacher, read them and provide information on the topic which is contained in the text (not all information they know from other sources). After a short introduction of the content the dialogue starts, when teacher asks questions or requires explanations of selected professional expressions or grammar items. For some students this assessment format is difficult mainly because of the necessity to speak actively - IT students (and experts as well) sometimes have problems to express their ideas in the form which is appropriate to the listener, regardless they speak Czech or English. This assessment format can help them eliminate this weakness.

Despite been traditionally and widely exploited in foreign language instruction, the Czech-English translation format was the least preferable one by students, as it does not give them much space to avoid using the required vocabulary or 
grammar item and thus show what they really learned. Numerous students in the research sample had the B2 knowledge before the semester started. They may feel they do not need to learn more as they are able to express themselves rather well. Then, they do not make much effort and consequently their knowledge does not increase much; in many cases students with lower starting level perform large efforts during the semester and reach better results at the end.

\section{LCI - AFQ correlations}

Within this step, the complete patterns (not single types of processors, as in table 1) of individual learning styles were considered. The data were processed by the SPSS statistic software by the method of multiple regression.

First, the coefficient of multiple regression (R) of the three assessment formats was calculated. The coefficient expresses how tight the correlation between the variables is, i.e. what the preference to an assessment format is with learners of different learning style patterns. Results are displayed in table 2.

Table 2: Multiple regression coefficient for written translation, oral dialogue and oral/written presentation

\begin{tabular}{|l|l|l|l|l|}
\hline Assessment format & $\mathbf{R}$ & $\begin{array}{l}\mathbf{R} \\
\text { Square }\end{array}$ & $\begin{array}{l}\text { Adjusted R } \\
\text { Square }\end{array}$ & $\begin{array}{l}\text { Std. Error of } \\
\text { the Estimate }\end{array}$ \\
\hline Written translation & .177 & .031 & .011 & 2.210 \\
\hline Oral dialogue & .212 & .045 & .025 & 1.892 \\
\hline Oral/written presentation & .227 & .052 & .032 & 2.712 \\
\hline
\end{tabular}

Coefficient of multiple regression ( $R$ ) can reach values from -1 to +1 . If the value is low, as in our cases, the statistical significance cannot be precisely proved. Therefore, the ANOVA test (analysis of variance) was applied to discover whether the learning style - assessment preference correlation is significant, or not. The results are displayed in table 3.

Table 3: ANOVA results for written translation, oral dialogue and oral/written presentation

\begin{tabular}{|l|c|c|}
\hline Assessment format & $\begin{array}{c}\text { Significance } \\
\text { value }\end{array}$ & Significant \\
\hline Written translation & .184 & No \\
\hline Oral dialogue & .062 & No \\
\hline Oral/written presentation & .034 & Yes \\
\hline
\end{tabular}

The result is statistically significant, if the significance value $<.05$, i.e. the statistically significant correlation was discovered between the learning style 
SlovakEdu, o.z.

pattern and the assessment format of oral/written presentation. To get a more detailed information, significance of single types of processors were calculated. The only significant correlations were discovered between oral/written presentation format with sequential processors and written translation format with technical processors. The results are displayed in table 4 .

Table 4 Significance values in LS/AF

\begin{tabular}{|l|l|l|l|}
\hline \multicolumn{1}{|c|}{ LS/AF } & $\begin{array}{c}\text { Written } \\
\text { translation }\end{array}$ & $\begin{array}{c}\text { Oral } \\
\text { dialogue }\end{array}$ & $\begin{array}{c}\text { Oral/written } \\
\text { presentation }\end{array}$ \\
\hline Sequential & .964 & .256 & .011 \\
\hline Precise & .145 & .122 & .313 \\
\hline Technical & .038 & .268 & .465 \\
\hline Confluent & .817 & .209 & .435 \\
\hline
\end{tabular}

LS: learning style; AF: assessment format

Significance value $<.05$

Reflecting the statistic results displayed in tables 2 - 4, we can conclude that the hypothesis

H1: There exists preference of written Czech-English translation with students of different learning style/s was falsified;

H2: There exists preference of oral dialogue with students of different learning style/s was falsified;

H3: There exists preference of oral/written presentation with students of different learning style/s was verified.

\section{Discussions and Conclusions}

To sum up, the assessment formats applied in subjects of ESP $1-4$ are considered appropriate for more than half of the respondents (see figure 1). Of course, we agree with objections of the other students saying their preferences are not accommodated and they thus cannot completely show what they learned. Therefore, for the next academic year, we plan to conduct another research correlating learning and assessment preferences. As we are not sure and it has not been proved that students are able to set by themselves the appropriate assessment format reflecting their preferences and perform their knowledge within it, the main objective of the research will be to discover answer to this question. We expect it will be rather difficult for the students to define assessment formats and direct the process of assessment by themselves; therefore, the current assessment formats will be applied simultaneously in the 'pilot' year.

To discuss the discovered findings within the world context is rather difficult not numerous researches have been conducted within EFL or ESL, they are even 
fewer in ESP. However, the work by Chew and Ng (2016) should be mentioned. Authors compare the style of participation of foreign language learners in different discussion settings, either online, or face-to-face,; they consider learners' level of language knowledge and personality type (extrovert, introvert) within observations, survey and online feedback. As expected, the results showed that synchronous online setting helped balance the participation of ESL learners, particularly in the group of introverts and those with lower level of knowledge. Contrary to this, Soto and Ambrose (2016), whio did not assess the field of foreign language but mathematics, discovered that more authentic assessment formats were required, particularly those which enabled teachers to involve learners in the process. Therefore, screencast applications for mobile devices were used which record and save learners' answers (both oral and written) and thus enable teachers to re-call and analyze them later on.

Learning results in online courses in LMS, which also exploited in ESP 1 - 4, can be also assessed by the Knowledge Assembly (Knowla) tool which measures students' knowledge in any subject (including ESP) by collecting the set of arbitrarily sized scrambled fragments into a logical order using a web-based interface (Thompson, Braude, 2016). The testing of this tool is still in the initial phase; however, students mostly appreciated that the tool also considered their critical thinking applied within the process of assessment.

Generally, mobile devices have been widely exploited to enhance open and distributed learning of various subjects, and customization and personalization can be applied in this process to accommodate students' learning preferences. For this purpose, a customized digital learning system (CDLS) and personalized digital learning system (PDLS) were uploaded into students' mobile devices. They tailored the environment to learners' preferences. Hsieh and Chen (2016) discovered that students exploiting either CDLS, or PDLS had a similar level of pretest knowledge, as well as post-test scores; however, the CDLS users spent significantly more time on completing the tasks. Reflecting these findings authors suggested that the PDLS was useful for learners mainly to complete their tasks efficiently.

In the research of Iranian EFL students, Soltani and Rajabioon (2016) appreciate teachers' awareness of students VARK (Visual, Auditory, Read/write, Kinaesthetic) learning preferences, however, no assessment-relating results were not mentioned by the authors, as probably not discovered.

Last but not least, to support the complex approach to assessment, the written, reflective and dialogic feedback (WRDF) strategy was applied by Crimmmins et al. (2016). The strategy included three formats - students' pre- and post WRDF surveys, students' post-WRDF focus group and teachers' post-WRDF survey. The results discovered preference to processes combining all elements of the strategy and indicated its integral role from both the students' and teachers' view. 
Despite all the above mentioned, we are aware the results of our research cannot be generalized, particularly because of the limitations in the amount of respondents and the specialization of the sample group focusing on IT students in one subject (ESP) only. All the limitations should be challenging for further research activities in this field, particularly of those exploiting the latest, learners' motivation-supporting mobile technologies, to verify, or falsify the finding of the study by Coffield et al. (2004) who detected $50 \%$ of supporters and $50 \%$ of rejectors of learning style theories more than a decade later.

\section{Acknowledgment}

This work was supported by the Excellence 2016, Faculty of Informatics and Management, University of Hradec Kralove, Czech Republic.

\section{References}

Chew, S.Y., Ng, L.L. (2016). The relevance of personality and language proficiency on the participation style of ESL learners in face-to-face and online discussions. Asia-Pacific education researcher, 25(4), 605-613.

Coffield, F., Moseley, D., Hall, E., Ecclestone, K. (2004). Learning styles and pedagogy in post-16 learning. A systematic and critical review. London: Learning and Skills Research Centre.

Comenius, J. A. (1946). The Gate of Languages Unlocked, or, A Seed-Plot of All Arts and Tongues: Containing a Ready Way to Learn the Latine and English Tongue. London: T.R. and N.T. for the Company of Stationers.

Crimmins, G., Nash, G., Oprescu, F., Liebergreen, M., Turley, J., Bond, R., Dayton, J. (2016). A written, reflective and dialogic strategy for assessment feedback that can enhance student/teacher relationship. Assessment\&Evaluation in higher education, 41(1), 141-153.

Felder, R.M. (2010). Are Learning Styles Invalid? (Hint: No!). http://www4.ncsu.edu/unity/lockers/users/f/felder/public/Papers/LS_Vali dity(On-course).pdf.

Honey, P. et al. (2000). Attitudes to e-learning: A national survey 2000 undertaken by the Campaign for learning. Sandford: Southgate Publishers.

Honey, P., Mumford, A. (2002). Using your learning styles. Maidenhead: Peter Honey Publications.

Honey, P. (2010). Learning styles - the key to personalised e-learning. www.bbmatters.net/bb_matters.../Learning\%20styles_peter\%20honey.pdf.

Hsieh, C.W., Chen, S.Y. (2016). A cognitive style perspective to handheld devices: customization vs. personalization. International review of research in open and distributes learning, 17(1), 1-22.

Johnston, C. A. (1996). Unlocking the will to learn. Thousand Oaks: Corwin Press Inc. 
Kolb, A. Y., Kolb, D. A. (2005). Learning Styles and Learning Spaces: Enhancing Experiential Learning in Higher Education. Acad Manag Learn Edu, 4(2), 193212.

Leither, A. (2011). Do student learning styles translate to different "testing styles? Journal of political science education, 7(4), 416-433.

Mitchell, D.P. et al. (2004). Learning style: a critical analysis of the concept and its assessment. London: Kogan Page.

Soltani, A., Rajabioon, Y. (2016). The role of teachers'awareness of learners' learning styles in Iranian EFL learners' vocabulary gains. Modern journal of language teaching methods, 6(3), 212-220.

Soto, M., Ambrose, R. (2016). Screencasts: formative assessment for mathematzical thinking. Technology knowledge and learning, 21(2), 277-283.

Šimonová, I., Poulová, P. (2012). Learning style reflection in tertiary e-education. Hradec Kralove: WAMAK.

Šimonová, I. (2013). Multimedia in the Teaching of Foreign Languages. JoLaCE Journal of Language and Cultural Education, 1(1), 112-121.

Šimonová, I. (2015). Mobile-assisted ESP learning in technical education. JoLaCe Journal of Language and Cultural Education, 1(3), 3-25.

Thompson, M.M., Braude, E.J. (2016). Evaluation of Knowla. Journal of educational computong research, 54(4), 483-512.

\section{Contact}

Assoc. Prof. PhDr. Ivana Simonova, PhD.

University of Hradec Kralove

Rokitanskeho 62

50003 Hradec Kralove, Czech Republic

ivana.simonova@uhk.cz 